\title{
ANALISIS KEKUATAN BALOK BETON AKIBAT PEMUTUSAN PENGECORAN
}

\author{
Erwin Susanto ${ }^{1}$, Tony Hartono Bagio ${ }^{2}$ \\ ${ }^{1}$ Erwin Susanto, Program Studi Teknik Sipil, Universitas Narotama, email: erwin_huga@yahoo.com; \\ ${ }^{2}$ Tony Hartono Bagio, Program Studi Teknik Sipil, Universitas Narotama, email: \\ tonyhartonobagio@yahoo.co.id
}

\begin{abstract}
ABSTRAK
Metode pemutusan pengecoran pada area seperempat bentang sudah sering dilakukan di proyek-proyek, hal ini dikarenakan adanya faktor peralatan, material cor, kesiapan lahan cor maupun cuaca yang tidak mendukung. Pengawas akan mengijinkan pemutusan ini dengan syarat permuakaan beton harus kasar agar ketika dilakukan pengecoran selanjutnya hasilnya diharapkan menjadi satu kesatuan, maka untuk mendapatkan permukaan beton yang kasar maka seringkali pelaksanaan dilapangan menggunakan air gula sebagai bahan penghambat pengerasan beton, sehingga ketika disemprot dengan air, permukaan beton menjadi kasar. Kekhawatiran terhadap hasil pemutusan pengecoran tersebut adalah dapat melemahkan kekuatan beton. Metode ini membandingkan kekuatan balok beton yang tidak mengalami pemutusan pengecoran dengan balok beton yang diputus pengecorannya pada seperempat bentang, metode pemutusannya adalah menggunakan kawat ayam dan air gula, kemudian setelah 24 jam dilanjutkan pengecoran berikutnya. Dari hasil perbandingan tesebut diketahui penggunaan air gula dalam proses pengkasaran permukaan beton dapat menurunkan kekuatan balok sebesar $39.62 \%$, sehingga penggunaan air gula tidak disarankan. metode pemutusan pengecoran dengan menggunakan kawat ayam dengan posisi miring $45^{\circ}$ mengalami penurunan kekuatan sebesar $11.32 \%$, sehingga metode pemutusan seperti ini dapat diterima.
\end{abstract}

Kata kunci: kekuatan balok beton, siar pengecoran, stop cor, air gula, kawat ayam

\section{PENDAHULUAN}

Banyak metode yang digunakan dalam proses pengecoran, ada yang menggunakan metode pengecoran dalam satu waktu dan ada juga pengecoran secara bertahap (siar), tentu tetap harus memperhatikan mutu dan kualitas dari hasil pengecoran tersebut, sehingga hasil pengecoran akan sesuai dengan yang direncanakan (SNI - 03 - 2847,2013). Kuat lentur beton adalah kemampuan balok yang diletakan pada dua tumpuan untuk menahan gaya dengan arah tegak lurus sumbu benda uji, yang diberikan kepadnya, sampai benda uji patah, dinyatkan dalam Mega Pascal (MPa) gaya persatan luas (SNI 034431,2011). Berdasarkan (SNI 03-4154-1996) Balok uji harus memenuhi ketentuanketentuan sebagai berikut:

1. SNI 03-2493-1991 tentang Metode Pembuatan dan Perawatan Benda Uji Beton di laboratorium yang berlaku untuk balok uji lentur dengan panjang balok empat kali lebar balok, tinggi balok lebih besar dri lebar balok untuk lebar balok $150 \mathrm{~mm}$.

2. Semua bidang permukaan harus rata dan bebas dari cacat goresan, lubang-lubang dan lekukan-lekukan.

3. Bidang-bidang samping harus tegak lurus terhadap bidang atas dan bidang bawahnya. 


\section{NAROTAMA JURNAL TEKNIK SIPIL \\ e-ISSN: 2460-3430}

VOLUME 4 NOMOR 2 NOPEMBER 2020

\section{METODE PENELITIAN}

Dalam pelaksanaan metode penghentian pengecoran dilakukan pada area $1 / 4$ bentang atau $1 / 4$ dari jarak tumpuan, karena pada posisi area tersebut momen yang dipikul balok adalah bernilai 0 (http://www.ilmusipil.com). Pemutusan pengecoran dengan menggunakan kawat ayam sebagai batas pengecoran sudah sering dilakukan di suatu pekerjaan proyek, fungsi dari kawat ayam pada proyek tersebut adalah untuk menghambat atau mencegah material beton untuk masuk kedaerah block out atau stop cor (http://digilib.mercubuana.ac.id) Penambahan kadar gula terhadap berat semen dapat semakin memperlama waktu pengerasan semen hingga pada kadar tertentu (pada kadar 0,15\%), kemudian waktu pengerasan kembali turun bila gula yang diberikan semakin banyak (Puryanto ,Moch. Absor dan Agus Subrianto, 2014). Langkah-langkah pembuatannya adalah sebagai berikut:

1. Panaskan 5 liter air.

2. $0.5 \mathrm{~kg}$ tepung kanji di campur dengan air biasa .

3. Kemudian cairan kanji disaring dengan saringan.

4. Air yang sudah panas $\pm 70^{\circ} \mathrm{C}$ di campur dengan $1 \mathrm{~kg}$ gula 5 . Masukkan cairan kanji kedalam Air dan diaduk.

6. Sebelum air mendidih diangkat dan siap digunakan.

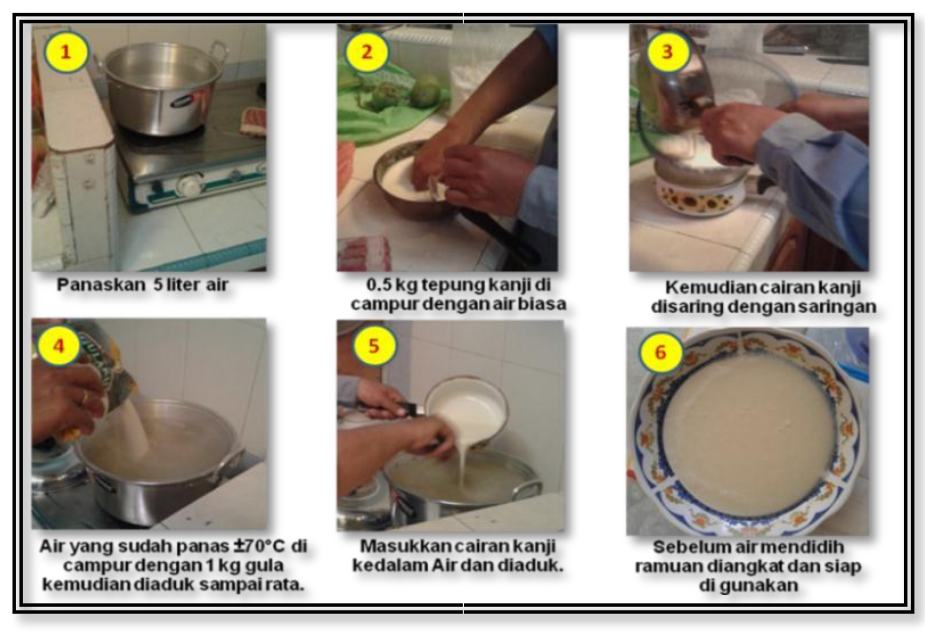

Gambar 1. Proses Pembuatan Air Gula

Sesuai SNI 03-4154 (1996) Balok uji harus memenuhi ketentuan-ketentuan sebagai berikut:

1. SNI 03-2493 (1991) tentang Metode Pembuatan dan Perawatan Benda Uji Beton di laboratorium yang berlaku untuk balok uji lentur dengan panjang balok empat kali lebar balok, tinggi balok lebih besar dri lebar balok untuk lebar balok $150 \mathrm{~mm}$.

2. Semua bidang permukaan harus rata dan bebas dari cacat goresan, lubang-lubang dan lekukan-lekukan.

3. Bidang-bidang samping harus tegak lurus terhadap bidang atas dan bidang bawahnya. 
Pada benda uji ini menggunakan besi tulangan dengan ukuran diameter $10 \mathrm{~mm}$ fy $=245$ $\mathrm{MPa}$ (hasil tes terlampir) untuk tulangan utama sebanyak 4 buah dan sengkang diameter $6 \mathrm{~mm}$ dengan jarak $15 \mathrm{~cm}$.

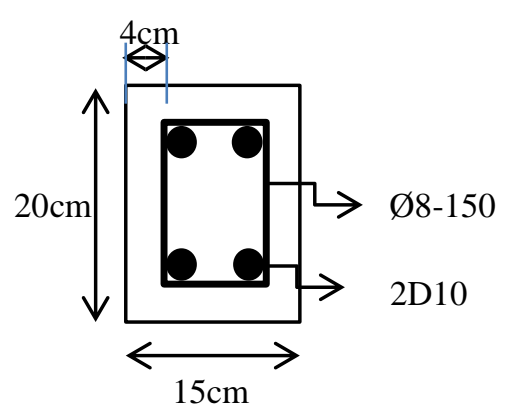

Gambar 2. Ilustrasi Pembesian

Untuk metode pembuatan benda uji dibagi menjadi 3 jenis benda uji masing-masing jenis terdiri dari 3 benda uji sehingga jumlah benda uji keseluruhan adalah 9 buah. Adapun jenis benda uji tersebut adalah sebagai berikut:

1. Benda uji dengan pengecoran utuh tanpa pemutusan, dimana pengecoran dilakukan sekaligus.

2. Benda uji dengan pengecoran yang dilakukan pemutusan pada $1 / 4 \mathrm{~L}$ (bentang) balok. Cara pemutusan dengan menggunakan kawat ayam sebagai batas pengecoran tahap pertama dengan kemiringan $45^{\circ}$, kemudian dilanjutkan pengecoran tahap kedua setelah selang waktu 24 jam.

3. Benda uji dengan pengecoran yang dilakukan pemutusan pada $1 / 4 \mathrm{~L}$ (bentang) balok. Cara pemutusan dengan menggunakan multipleks yang dilapisi air gula sebagai batas pengecoran tahap pertama, kemudian setelah 8 jam multipleks pembatas dibongkar setelah selang waktu 24 jam dilanjutkan pengecoran tahap kedua 
NAROTAMA JURNAL TEKNIK SIPIL

e-ISSN: 2460-3430

VOLUME 4 NOMOR 2 NOPEMBER 2020

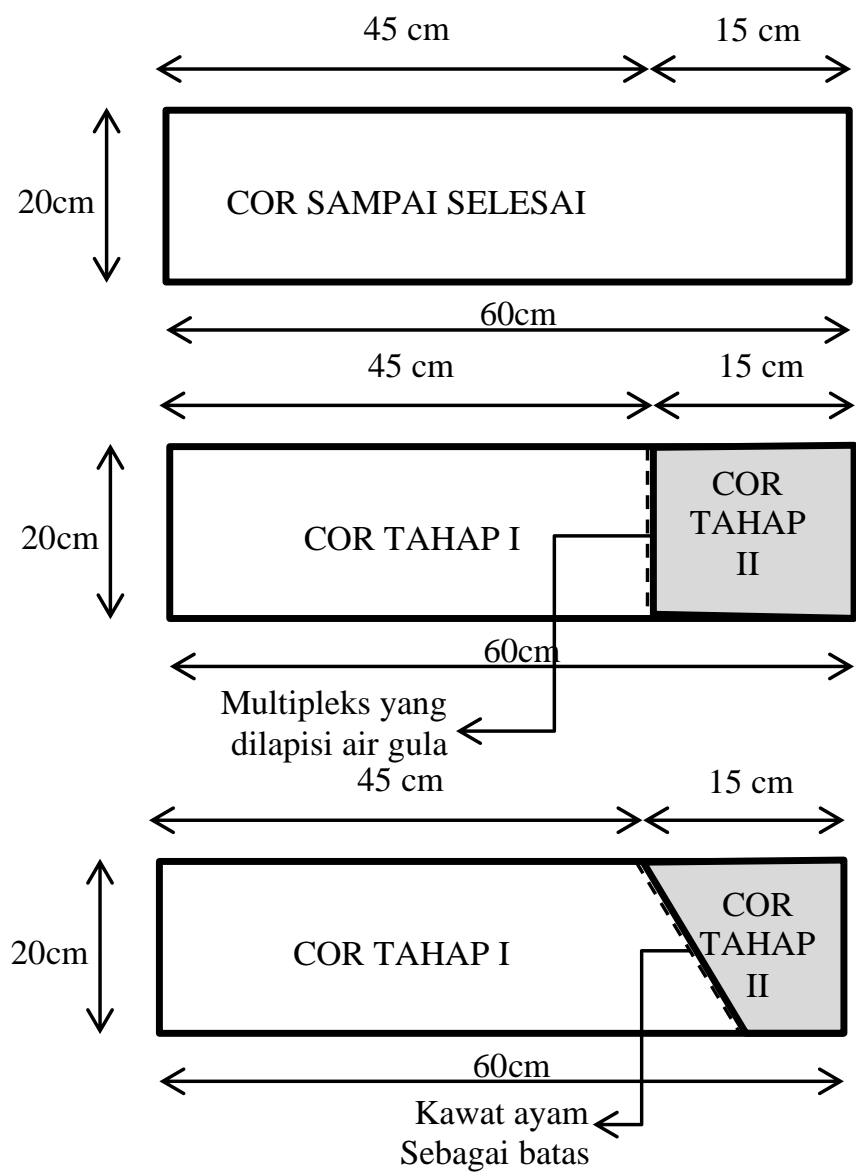

Gambar 4. Ilustrasi Tiga Type Pemutusan Pengecoran

Berdasarkan benda uji balok yang telah disiapkan sebelumnya, dilakukan tes lentur setelah balok beton berumur minimal 28 hari. Dengan metode pengujian sesuai dengan (SNI 034154-1996)

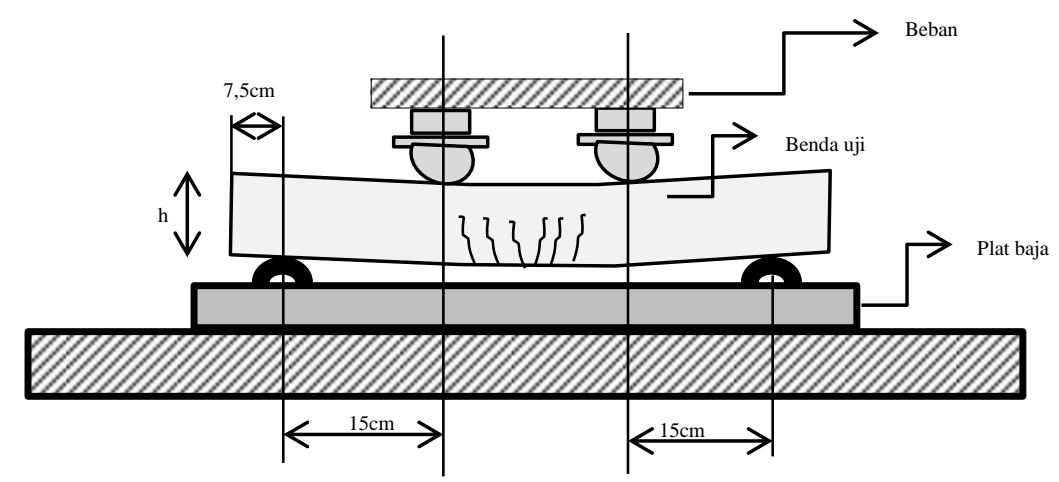

Gambar 5. Ilustrasi Tes Lentur 
NAROTAMA JURNAL TEKNIK SIPIL

e-ISSN: 2460-3430

VOLUME 4 NOMOR 2 NOPEMBER 2020

\section{HASIL PENELITIAN}

Tabel 1: Hasil Pengujian Kuat Lentur Balok Beton Tanpa Pemutusan

\begin{tabular}{|c|c|l|}
\hline Nomor & BEBAN $(\mathrm{P})(\mathrm{kg})$ & \multicolumn{1}{|c|}{ KETERANGAN } \\
\hline A1 & $21,000.00$ & Retak pada posisi tengah \\
A2 & $17,000.00$ & Retak pada posisi tengah \\
A3 & $15,000.00$ & Retak pada posisi tengah \\
\hline
\end{tabular}

Tabel 2: Hasil Pengujian Kuat Lentur Dengan Pemutusan 1/4 L Tegak $90^{\circ}$

\begin{tabular}{|c|c|c|}
\hline Nomor & BEBAN $(\mathrm{P})(\mathrm{kg})$ & KETERANGAN \\
\hline B1 & $11,000.00$ & Retak pada posisi pemutusan \\
B2 & $11,000.00$ & Retak pada posisi pemutusan \\
B3 & $10,000.00$ & Retak pada posisi pemutusan \\
\hline
\end{tabular}

Tabel 3: Hasil Pengujian Kuat Lentur Dengan Pemutusan 1/4 L Miring 45

\begin{tabular}{|c|c|c|}
\hline Nomor & BEBAN $(\mathrm{P})(\mathrm{kg})$ & KETERANGAN \\
\hline $\mathrm{C} 1$ & $16,000.00$ & Retak pada posisi tengah \\
$\mathrm{C} 2$ & $20,000.00$ & Retak pada posisi tengah \\
$\mathrm{C} 3$ & $11,000.00$ & Retak pada posisi tengah \\
\hline
\end{tabular}

Tabel 4: Resume Hasil Pengujian Kuat Lentur

\begin{tabular}{|c|c|c|c|c|c|c|}
\hline NOMOR & $\begin{array}{c}\text { KODE } \\
\text { BENDA } \\
\text { UJI }\end{array}$ & $\begin{array}{c}\text { BERAT } \\
\text { BENDA } \\
\text { UJI } \\
\end{array}$ & $\begin{array}{l}\text { RATA - } \\
\text { RATA }\end{array}$ & BEBAN UJI (KG) & RATA - RATA & KETERANGAN \\
\hline \multirow[t]{3}{*}{1} & A1 & 44.05 & \multirow{3}{*}{43.87} & $21,000.00$ & \multirow{3}{*}{$17,666.67$} & ORI (TANPA PEMUTUSAN) \\
\hline & A2 & 44.12 & & $17,000.00$ & & ORI (TANPA PEMUTUSAN) \\
\hline & A3 & 43.44 & & $15,000.00$ & & ORI (TANPA PEMUTUSAN) \\
\hline \multirow[t]{3}{*}{2} & $\mathrm{~B} 1$ & 44.11 & \multirow{3}{*}{43.79} & $11,000.00$ & \multirow{3}{*}{$10,666.67$} & TEGAK (AIR GULA) \\
\hline & B2 & 43.85 & & $11,000.00$ & & TEGAK (AIR GULA) \\
\hline & B3 & 43.42 & & $10,000.00$ & & TEGAK (AIR GULA) \\
\hline \multirow[t]{3}{*}{3} & $\mathrm{C} 1$ & 44.04 & \multirow{3}{*}{44.11} & $16,000.00$ & \multirow{3}{*}{$15,666.67$} & MIRING (KAWAT AYAM) \\
\hline & $\mathrm{C} 2$ & 44.15 & & $20,000.00$ & & MIRING (KAWAT AYAM) \\
\hline & $\mathrm{C} 3$ & 44.13 & & $11,000.00$ & & MIRING (KAWAT AYAM) \\
\hline
\end{tabular}


NAROTAMA JURNAL TEKNIK SIPIL

e-ISSN: 2460-3430

VOLUME 4 NOMOR 2 NOPEMBER 2020

Dari hasil pengujian balok beton di laboratorium dapat dihitung momen maksimal berdasarkan nilai $\mathrm{P}$ yang ada.

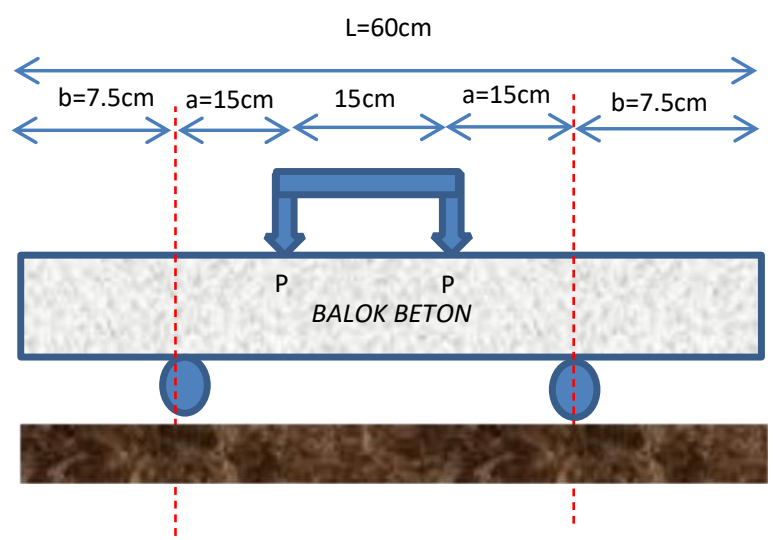

Gambar 4.1: Gambar Ilustrasi Posisi Beban

(Sumber: SNI 03-4154-1996 digambar ulang)

Persamaan:

$$
\left.M=P x a+1 / 8 x q x L^{2}+3 / 4 x q x L x a\right)
$$

Dimana :

$$
\begin{aligned}
& \mathrm{M}=\text { Momen maksimal } \\
& \mathrm{L}=\text { Bentang balok } \\
& \mathrm{P}=\text { Beban yang diberikan alat uji } \\
& \mathrm{q}=\text { Beban merata balok beton (didapatkan dari setiap berat balok beton) } \\
& \mathrm{a}=\text { Jarak antara tumpuan dengan } \mathrm{P}
\end{aligned}
$$

\begin{tabular}{|c|c|c|c|c|c|c|c|c|c|c|c|c|}
\hline $\begin{array}{c}\text { TYPE } \\
\text { BALOK }\end{array}$ & \multicolumn{3}{|c|}{$\begin{array}{l}\text { DIMENSI } \\
\text { BALOK } \\
\text { (m) }\end{array}$} & $\begin{array}{l}\text { Vol. } \\
\left(\mathrm{m}^{3}\right)\end{array}$ & $\begin{array}{c}\text { BERAT } \\
\text { BENDA UJ } \\
\text { (Kg/Balok) }\end{array}$ & $\begin{array}{c}\text { BERAT } \\
\text { RATA- } \\
\text { RATA } \\
\text { (Kg) }\end{array}$ & $\begin{array}{l}\text { BERAT } \\
\text { JENIS } \\
(\mathrm{Kg} / \mathrm{m})\end{array}$ & $\begin{array}{c}\text { (q) } \\
\mathrm{Kg} / \mathrm{m}^{\prime}\end{array}$ & $q(N / m)$ & $\begin{array}{l}\text { P HASIL UJI } \\
\text { LENTUR } \\
\text { DI LAB }\end{array}$ & $1 / 2 \mathrm{P}(\mathrm{Kg})$ & $P(\mathrm{Nm})$ \\
\hline 1 & $\mathrm{p}$ & 1 & $\mathrm{t}$ & 2 & 3 & 4 & 5 & 6 & 7 & 8 & 9 & 10 \\
\hline A1 & 0.6 & 0.2 & 0.2 & 0.018 & 44.05 & & $2,447.22$ & 73.417 & 719.483 & 21,000 & 10,500 & 102,900 \\
\hline A2 & 0.6 & 0.2 & 0.2 & 0.018 & 44.12 & 43.870 & $2,451.11$ & 73.533 & 720.627 & 17,000 & 8,500 & 83,300 \\
\hline A3 & 0.6 & 0.2 & 0.2 & 0.018 & 43.44 & & $2,413.33$ & 72.400 & 709.520 & 15,000 & 7,500 & 73,500 \\
\hline B1 & 0.6 & 0.2 & 0.2 & 0.018 & 44.11 & & $2,450.56$ & 73.517 & 720.463 & 11,000 & 5,500 & 53,900 \\
\hline B2 & 0.6 & 0.2 & 0.2 & 0.018 & 43.85 & 43.793 & $2,436.11$ & 73.083 & 716.217 & 11,000 & 5,500 & 53,900 \\
\hline B3 & 0.6 & 0.2 & 0.2 & 0.018 & 43.42 & & $2,412.22$ & 72.367 & 709.193 & 10,000 & 5,000 & 49,000 \\
\hline C1 & 0.6 & 0.2 & 0.2 & 0.018 & 44.04 & & $2,446.67$ & 73.400 & 719.320 & 16,000 & 8,000 & 78,400 \\
\hline C2 & 0.6 & 0.2 & 0.2 & 0.018 & 44.15 & 44.107 & $2,452.78$ & 73.583 & 721.117 & 20,000 & 10,000 & 98,000 \\
\hline
\end{tabular}

Tabel 5: Hasil Perhitungan Momen Maksimal Pada Balok Beton 
NAROTAMA JURNAL TEKNIK SIPIL

e-ISSN: 2460-3430

VOLUME 4 NOMOR 2 NOPEMBER 2020

\begin{tabular}{|c|c|c|c|c|c|c|c|c|c|c|c|c|}
\hline C3 & 0.6 & 0.2 & 0.2 & 0.018 & 44.13 & & $2,451.67$ & 73.550 & 720.790 & 11,000 & 5,500 & 53,900 \\
\hline
\end{tabular}

Tabel 5: Hasil Perhitungan Momen Maksimal Pada Balok Beton (sambungan)

\begin{tabular}{|c|c|c|c|c|c|c|c|c|c|c|}
\hline $\begin{array}{c}\text { TYPE } \\
\text { BALOK }\end{array}$ & \multicolumn{3}{|c|}{$\begin{array}{l}\text { DIMENSI } \\
\text { BALOK } \\
\text { (m) }\end{array}$} & $\begin{array}{l}\text { Vol. } \\
\left(\mathrm{m}^{3}\right)\end{array}$ & $\begin{array}{c}1 / 2 \mathrm{P} \\
(\mathrm{kg})\end{array}$ & $\begin{array}{c}P \\
(\mathrm{Nm})\end{array}$ & $\begin{array}{c}\text { MOMEN (Nm) } \\
=\left(P^{*} a\right)+\left(1 / 8^{*} q^{*} L^{\wedge} 2\right) \\
+\left(3 / 4^{*} q^{*} L^{*} a\right)\end{array}$ & $\begin{array}{l}\text { MOMEN } \\
\text { RATA-RATA } \\
(\mathbf{N m})\end{array}$ & PROSENTASE & DEVIASI \\
\hline 1 & $\mathrm{p}$ & 1 & $\mathrm{t}$ & 2 & 9 & 10 & 11 & 12 & 13 & 14 \\
\hline A1 & 0.6 & 0.2 & 0.2 & 0.018 & 10,500 & 102,900 & $15,515.94$ & & & \\
\hline A2 & 0.6 & 0.2 & 0.2 & 0.018 & 8,500 & 83,300 & $12,576.07$ & $13,065.61$ & $100 \%$ & - \\
\hline A3 & 0.6 & 0.2 & 0.2 & 0.018 & 7,500 & 73,500 & $11,104.82$ & & & \\
\hline B1 & 0.6 & 0.2 & 0.2 & 0.018 & 5,500 & 53,900 & $8,166.05$ & & & \\
\hline B2 & 0.6 & 0.2 & 0.2 & 0.018 & 5,500 & 53,900 & $8,165.57$ & $7,920.47$ & $60.62 \%$ & $39.38 \%$ \\
\hline B3 & 0.6 & 0.2 & 0.2 & 0.018 & 5,000 & 49,000 & $7,429.78$ & & & \\
\hline C1 & 0.6 & 0.2 & 0.2 & 0.018 & 8,000 & 78,400 & $11,840.92$ & & & \\
\hline $\mathrm{C} 2$ & 0.6 & 0.2 & 0.2 & 0.018 & 10,000 & 98,000 & $14,781.13$ & $11,596.05$ & $88.75 \%$ & $11.25 \%$ \\
\hline C3 & 0.6 & 0.2 & 0.2 & 0.018 & 5,500 & 53,900 & $8,166.09$ & & & \\
\hline
\end{tabular}

Keterangan:
[1] = type balok benda uji
[8] = hasil uji lentur *0.5
$[\mathrm{p}]=$ dimensi panjang balok
$[9]=[8] * 0.5$
[1] = dimensi lebar balok
$[10]=[9]^{*} 9.8$
$[\mathrm{t}]=$ dimensi tinggi balok
$[11]=([10] * a)+\left(1 / 8 *[7] * L^{\wedge} 2\right)+(3 / 4 *[7] * L$
$[2]=\mathrm{p}^{*} \mathrm{l}^{*} \mathrm{t}$
*a)
[3] = berat benda uji hasil lab $(\mathrm{kg})$
[12] = nilai momen rata-rata
[4] = berat rata-rata benda uji
$[5]=$ berat jenis balok $[3] /[2]$
$[6]=9.8 *[5]$
[7] = hasil uji lentur Ton
[13] = hasil prosentase terhadap nilai rata- rata benda uji A
[14] = deviasi prosentase terhadap benda uji A

\section{Catatan:}
A $=$ Balok beton tanpa pemutusan
$\mathrm{B}=$ Balok beton dengan pemutusan posisi tegak (dengan air gula)
$\mathrm{C} \quad=$ Balok beton dengan pemutusan posisi miring (dengan kawat ayam)

Dari data perhitungan nilai momen teoritis sebesar 7,363.30 Nm dibandingkan dengan nilai rata-rata momen perhitungan aktual untuk balok tanpa pemutusan type A dalam tabel 4.5 sebesar 13,065.61 $\mathrm{Nm}$ nilai prosentasenya adalah 7,363.30:13,065.61 x 100\%= $177,44 \%$. Sedangkan untuk perbandingan nilai $\mathrm{P}$ sesuai hasil pengujian pada tabel 4.4 , maka hasil rata-rata balok tanpa pemutusan pengecoran adalah $\mathrm{P}=17.666,67 \mathrm{~kg}$, balok dengan pemutusan pengecoran $1 / 4 \mathrm{~L}$ miring $45^{\circ}$ adalah $\mathrm{P}=15.666,67 \mathrm{~kg}$, sedangkan untuk 
balok dengan pemutusan tegak nilai rata-rata adalah $\mathrm{P}=10.666,67 \mathrm{~kg}$. Sehingga prosentase perbandingannya dapat dilihat sesuai tabel berikut:

Tabel 6: Perbandingan Nilai Beban Pengujian

\begin{tabular}{|c|c|c|c|c|c|c|}
\hline NOMOR & $\begin{array}{c}\text { KODE } \\
\text { BENDA } \\
\text { UJI }\end{array}$ & $\begin{array}{c}\text { BERAT } \\
\text { BENDA } \\
\text { UJI }\end{array}$ & $\begin{array}{c}\text { P BEBAN } \\
\text { RATA-RATA } \\
\text { HASIL } \\
\text { PENGUJIAN } \\
\text { (KG) }\end{array}$ & KETERANGAN & PROSENTASE & \begin{tabular}{|c} 
SELISIH \\
TERHADAP \\
BALOK ORI
\end{tabular} \\
\hline \multirow[t]{3}{*}{1} & A1 & 44.05 & \multirow{3}{*}{$17,666.67$} & ORI (TANPA PEMUTUSAN) & \multirow{3}{*}{$100.00 \%$} & \\
\hline & A2 & 44.12 & & ORI (TANPA PEMUTUSAN) & & \\
\hline & A3 & 43.44 & & ORI (TANPA PEMUTUSAN) & & \\
\hline \multirow[t]{3}{*}{2} & B1 & 44.11 & \multirow{3}{*}{$10,666.67$} & TEGAK (AIR GULA) & \multirow{3}{*}{$60.38 \%$} & \multirow{3}{*}{$39.62 \%$} \\
\hline & B2 & 43.85 & & TEGAK (AIR GULA) & & \\
\hline & B3 & 43.42 & & TEGAK (AIR GULA) & & \\
\hline \multirow[t]{3}{*}{3} & $\mathrm{C} 1$ & 44.04 & \multirow{3}{*}{$15,666.67$} & MIRING (KAWAT AYAM) & \multirow{3}{*}{$88.68 \%$} & \multirow{3}{*}{$11.32 \%$} \\
\hline & $\mathrm{C} 2$ & 44.15 & & MIRING (KAWAT AYAM) & & \\
\hline & $\mathrm{C} 3$ & 44.13 & & MIRING (KAWAT AYAM) & & \\
\hline
\end{tabular}

\section{KESIMPULAN}

1) Penggunaan air gula dalam proses pengkasaran permukaan beton dapat menurunkan kekuatan balok sebesar $39.62 \%$ (tabel 4.6), sehingga penggunaan air gula tidak disarankan.

2) Metode pemutusan pengecoran dengan menggunakan kawat ayam dengan posisi miring $45^{\circ}$ mengalami penurunan kekuatan sebesar $11.32 \%$ (tabel 4.6), sehingga metode pemutusan seperti ini dapat diterima.

3) Penggunaan air gula dalam proses pengkasaran permukaan beton dapat menurunkan momen balok sebesar 39.38\% (tabel 4.5) dari balok tanpa pemutusan, sedangkan untuk balok dengan pemutusan posisi miring $45^{\circ}$ mengalami penurunan momen kapasitas balok sebesar $11.25 \%$.

4) Nilai momen balok dengan hasil pengujian tanpa pemutusan dibanding dengan nilai teoritis terdapat faktor keamanan sebesar $177,44 \%$.

\section{DAFTAR PUSTAKA}

Ahadi (2009). Kelebihan Dan Kekurangan Beton Sebagai Material Bangunan. Sumber: Http://Www.Ilmusipil.Com/Kelebihan-Dan-Kekurangan-Beton -Sebagai-Material-Bangunan. Diakses Tanggal 10 Maret 2016

Bagio, Tony Hartono (2014). Konstruksi Beton I. Diktat Kuliah Universitas Narotama. Surabaya Dipohusodo, Istimawan (1993). Struktur Beton Bertulang. Jakarta.Dpu.

G.,Nawy Edward, Tavio, Benny Kusuma (2010). Beton Bertulang Sebuah Pendekatan Mendasar Edisi Kelima. Surabaya. ITS Press 


\section{NAROTAMA JURNAL TEKNIK SIPIL}

e-ISSN: 2460-3430

VOLUME 4 NOMOR 2 NOPEMBER 2020

Gideon Kusuma Dan W.C Vis (1993). Dasar-Dasar Perencanaan Beton Bertulang. Jakarta.Erlangga

Mc.Cormac, Jack C (2014). Design of Reinforced Concrete Ninth Edition. USA: Wiley.

Marsudi, M. Tri Rochadi, Nur Setiaji P., Stefanus Santoso (2004). Modifikasi Balok Beton Tulangan Komposit Guna Meningkatkan Daktilitas Pada Konstruksi Bangunan Gedung.9. 60 67

PBI-1971 (1971).Peraturan Beton Bertulang Indonesia. Bandung.DPU.

SNI-03-2847-2002 (2002). Tata Cara Perhitungan Struktur Beton Untuk Bangunan Gedung. Jakarta.BSN.

SNI 03-4154-1996 (1996). Metode Pengujian Kuat Lentur Beton Dengan Balok Uji Sederhana Yang Dibebani Terpusat Langsung. Jakarta: BSN.

SNI 4431-2011 (2011). Cara Uji Kuat Lentur Beton Normal Dengan Dua Titik Pembebanan. Jakarta: BSN.

Technical Data Sheet (2007). Rugasol C Surface Retarder for Concrete. Jakarta: PT. Sika Indonesia 